\title{
ANALYSIS OF OPTIMAL PORTFOLIO PERFORMANCE IN KOMPAS 100 AND LQ 45 OF INDONESIA STOCK EXCHANGE
}

\author{
Astuty Pudji ${ }^{1}$, Faisal Ahmad ${ }^{2}$, Yolanda $^{1 *}$ \\ ${ }^{1}$ Faculty of Economics, University of Borobudur, Jakarta, Indonesia \\ ${ }^{2}$ Master's Program in Management, University of Dirgantara Marsekal Suryadarma, \\ Indonesia \\ *E-mail: indah eds@yahoo.com
}

\begin{abstract}
This study aims to analyze the formation of optimal portfolios in Kompas 100 and LQ 45 stocks. The research methodology used in the formation of optimal portfolios is Single Index Model, Constant Correlation Model, and Markowitz Model by measuring portfolio performance using the Sharpe Index, Treynor Index, and Jensen Index. Based on the results, (1) the proportion of the optimal portfolio with the highest return generated in Kompas 100 stocks using the Single Index Model method. (2) The Kompas 100 portfolio has the highest Sharp, Treynor, and Jensen Index values compared to the LQ 45 portfolio with the Single Index Model, Constant Correlation Model, and Markowitz Model. (3) Calculation of optimal portfolio with Single Index Model shows better performance than Constant Correlation Model and Markowitz Model for both Kompas 100 and LQ 45.
\end{abstract}

\section{KEY WORDS}

Compass 100 Index, LQ 45 Index, optimal portfolio, single index model, constant correlation model, Markowitz model, Sharpe Index, Treynor Index, Jensen Index.

The capital market is currently growing; this development can be seen among others from the increase in the number of issuers, market capitalization, investment actors, and Composite Daily Stock Index. The increase can be seen, one of which is from the value of the $\mathrm{JCl}$, which was around IDR 5,500 in 2016 and the Composite Stock Price Index (CSPI) was at the level of 6355.65 in 2017-the highest closing level for the $\mathrm{JCl}$ in 2017 . This indicates that the capital market is one of the attractive alternatives in investing and according to Partono et al. (2017), investment is starting to become a necessity in the community in Indonesia. Gautam \& Singh (2014) affirm risks and returns play an important role in making investment decisions.

To get the maximum profit in investing in the Stock Exchange, investors must conduct investment analysis. Investment analysis can be an analysis of internal and external factors. An internal factor analysis can be an analysis of the company's financial performance. According to Yolanda (2018), corporate governance can affect company performance and for banking companies, capital adequacy can be influenced by the company's financial ratios (Yolanda, 2017).

Analysis carried out by investors can help in determining an efficient portfolio that provides the greatest expected return with the same level of risk or a portfolio that contains the smallest risk with the same level of expected return. Of the many choices available in a collection of efficient portfolios, investors will choose the optimal portfolio that best fits their investment policy.

According to Thomas et al. (2017), rational investors will choose investments in companies that have a single index model analysis. Fadila Paramitha and Achmad Anggono (2013) find an efficient and optimal portfolio, based on the Modern Markowitz Portfolio Theory using the aad in solver tool, with the result is the highest Sharpe ratio showing better performance and having a higher risk, in line with the results of research by Pinasthika and Surya (2014). Nugroho (2018) states that with the Sharpe, Treynor, and Jensen Index method, Business Indexs 27 is superior to IDX 30, but Business Index 27 is more sensitive in 
changing market returns. Arna Suryani and Eva Herianti (2015) state that the Treynor index shows consistent results from the measurement of LQ 45 stock performance.

The Indonesian Capital Market has many stock indices; several that are often of concern are Kompas 100, LQ 45, and JII because the three indices consist of companies that have large market capitalization and their liquid stocks are traded, so that it attracts investors.

Therefore, the research problemsin this study are: (1) Is there an optimal portfolio in Kompas 100 and LQ 45 stocks generated from the Single Index Model, Constant Correlation Model, and Markowitz Model method? (2) How is the comparison of the performance of the Kompas 100 and LQ 45 optimal portfolios? (3) How is the ratio of optimal portfolio performance formed based on the method of Single Index Model, Constant Correlation Model, and Markowitz Model?

\section{LITERATURE REVIEW}

Optimal Portfolio. Efficient portfolios are defined as portfolios with the highest returns on certain risks or portfolios with the lowest risk for certain returns. According to T. N. Sari1 et al. (2017), portfolios are categorized to be efficient when offering the expected maximum return for a certain level of risk or offering a minimum risk for the expected return. An optimal portfolio is a portfolio that is chosen from a large selection of portfolios available in efficient portfolios. Investors need to consider and determine what securities form a portfolio that can achieve maximum efficiency and be adjusted to the preferences of the investor concerned about the return and risk they are willing to bear.

Markowitz Model. Modern Portfolio Theory was discovered in 1952 by Harry Markowitz in his dissertation in the field of statistics. His discovery, entitled "Portfolio Selection" was first published in the Journal of Finance (Mangram, 2013). Modern Portfolio Theory, Optimal Portfolio is a technical finance theory equivalent to a statement "Don't put all your eggs in one basketball. If the basket is dropped, all eggs are broken; if placed in more than one basket, the risk that will be broken is dramatically reduced (Mangram, 2013)." Likewise in investing, risk can be reduced by diversifying namely placing funds in different stocks, different asset classes (such as bonds, derivative instruments, real estate, and so forth) and or for commodities such as gold or oil (Mangram, 2013). According to Markowitz, investing in many securities is not enough to minimize variance. In diversifying, investors need to avoid securities with high covariance. Investors should diversify into companies in different industries, especially those with different economic characteristics, because they have lower covariance than companies in the same industry. In addition, according to Markowitz, diversification cannot eliminate all risks because there will always be systematic risks that cannot be lost (Mangram, 2013). Portfolios that have a maximum expected return do not always have a minimum variance. Thus, the investor's portfolio choice is the one giving the maximum expected return on a certain variance or the portfolio with the smallest variance at a certain expected return (Zubir, 2013).

The Single Index Model. In 1963, William F. Sharpe developed the Single Index Model, which was a simplification of the Markowitz Portfolio Theory by reducing the number of variables that must be estimated. According to Zubir (2013), the Single Index Model is a technique to measure return and risk of a stock or portfolio.

The model assumes that stock return movements are only related to market movements. If the market moves up, in the sense that demands for stocks increases, then the price of stocks in the market will rise as well. Vice versa, if the market moves down, the stock price will also decrease, so it can be concluded that stock returns correlate with market returns (Husnan, 2005).

The Single Index Model divides the profit level of a stock into two parts, namely returns that are not affected by market changes $\left(\alpha_{i}\right)$ and returns that are affected by the market $\left(\beta_{i} R_{m}\right)$.. Beta $\left(\beta \_\mathrm{i}\right)$ shows the stock sensitivity level of the market index gains.

Furthermore, the Single Index Model divides the stock variance into two parts: unique risk $\left(\sigma_{e i}^{2}\right)$ and market-related risks $\left(\beta_{i}{ }^{2} \sigma_{m}^{2}\right)$. Meanwhile, covariance depends solely on market 
risk. This means that the Single Index Model shows that the only reason why stocks move together-this is that they react to market movements (Husnan, 2005).

The Constant Correlation Model. Elton, Gruber, and Padberg developed the Constant Correlation Model in 1978. The model assumes that the correlation coefficient between stocks is equal. In this model, the procedure used to form a portfolio is the same as in the Single Index Model, but the stock rating to form a portfolio uses excess return to standard deviation or ERS (Elton, 2014). To fulfill the assumption that the correlation coefficient of each stock is constant, the value used is the average value of the correlation.

\section{METHODS OF RESEARCH}

The population in this study is stocks included in the Kompas 100 and LQ 45 Index during the period of January 2013 to December 2017. The technique used in determining the sample is purposive sampling where the determination of samples is based on certain considerations.

The sample criteria used in this study are:

- Stocks listed on the Kompas 100 and LQ 45 from January 2013 to December 2017;

- Stocks consistently listed on the Kompas 100 and LQ 45 from January 2013 to December 2017.

Based on the results of the selection, there were 52 stocks on the Kompass Index 100 and 24 stocks on the LQ 45 that met the criteria of the sample in this study.

The Single Index Model. In the Single Index Model, stocks that have an excess return to beta (ERB) value that is higher or equal to the cutoff point value are stocks that will form an optimal portfolio. ERB and $\mathrm{Ci}$ are calculated using the following formula.

$$
E R B_{i}=\frac{E\left(R_{i}\right)-R_{f}}{\beta_{i}}
$$

Where: ERBi: excess return to beta stock I; $E(R i)$ : expected return to beta stock I; Rf: riskfree asset return; Bi: beta stock i.

$$
C_{i}=\frac{\sigma_{m}^{2} \sum_{j=1}^{t} A_{i}}{1+\sigma_{m}^{2} \sum_{j=1}^{t} B_{i}}
$$

Where: $\sigma_{\mathrm{m}}^{2:}$ market-return variance.

To find the proportion of a portfolio, the following formula is used:

$$
W_{i}=\frac{Z_{i}}{\sum_{j=1}^{k} Z_{j}}
$$

The $\mathrm{Zi}$ value can be searched by the following equation:

$$
Z_{i}=\frac{\beta_{i}}{\sigma_{e i}^{2}}(E R B-C *)
$$

The Constant Correlation Model. In Constant Correlation Model, stocks that have the value of excess return to standard deviation (ERS) that are higher or equal to the value of the cutoff point are stocks that will form an optimal portfolio. ERS and $\mathrm{Ci}$ are calculated using the following formula:

$$
E R S=\frac{\left(E\left(R_{i}\right)-\left(R_{f}\right)\right.}{\sigma_{i}}
$$


Where: E (Ri): Expected return security I; Rf: Free-risk return; бi: Standard deviation security i.

$$
C_{i}=\frac{\rho}{1-\rho+i \rho} \sum_{j=1}^{i} \frac{E\left(R_{j}\right)-R_{f}}{\sigma_{j}}
$$

Where: $\rho$ : Constant correlation coefficient; $E(R i)$ : Expected return security I; Rf: Free-risk return; oi: Standard deviation security i.

Assumed that $\rho$ has a constant correlation coefficient, the constant correlation value can be searched by the following formula:

$$
\rho=\frac{\sum_{i=1}^{N} \sum_{i=1}^{N} \rho i j}{N}
$$

The Markowitz Model. Markowitz model calculations are performed using a solver in Microsoft Excel with the following limitations:

- The sum of all $\mathrm{w}$ is one ( $\mathrm{W}$ total $=1)$;

- Each stock w value is greater or equal to zero (wi $>0)$ to avoid short sales;

- The portfolio expected return is the same as the expected target return $\left(E(R p)=E^{*}\right)$.

Solver is used to find a portfolio with minimal risk on a certain return, a portfolio that has the highest capital allocation line value will be chosen as the optimal portfolio. To calculate the expected return and risk of the Markowitz Model, the following formula is used:

$$
E(R p)=\sum_{j=1}^{n} E(R i) .(W i)
$$

Where: $E(R p)$ : portfolio expected return; $E(R i)$ : expected return of stock i investment; Wi: proportion of funds invested in stock $\mathrm{i}$.

The standard deviation can be searched from the square root of the portfolio or from the following equation:

$$
\sigma_{P}^{2}=\sum_{i=1}^{n} \sum_{j=1}^{n} w_{i} \cdot w_{j} . \sigma_{i j}
$$

Where: $\sigma p^{2}$ : Portfolio variance; Wi: Weight of stock I; Wj:Weight of stock j; $\sigma_{\mathrm{ij}}$ : Covariance between stocks $\mathrm{i}$ and $\mathrm{j}$.

According to Telelilin (2010), to calculate portfolio performance, the following formula is used:

$$
\text { Sharpe's Index }=\frac{R p-R f}{\sigma p}
$$

Where: S: The value of the Sharpe Ratio; Rp: Average portfolio returns; Rf: Average risk-free return rate; $\sigma \mathrm{p}$ : Total portfolio risk.

Sharpe index is a portfolio performance calculated based on the net result of a portfolio with a risk-free interest rate per unit.

$$
\text { Treynor Index }=\frac{R p-R f}{\beta p}
$$

Where: T: The value of the Treynor Ratio; Rp: Average portfolio returns; Rf: Average riskfree return rate; $\beta p$ : Portfolio systematic risk.

The Treynor Index is a metric for determining how much excess return was generated for each unit of risk taken on by a portfolio. 


$$
\text { Jensen Index }=R p-(R f+\beta p(R f-R m))
$$

Where: $\alpha$ : The value of the Jensen Ratio; Rp: Average portfolio returns; Rf: Average risk-free return rate; Rm: Average market return; Bp: Portfolio systematic risk.

In Jensen index, portfolio premium risk is influenced by the risk of premium markets.

\section{RESULTS AND DISCUSSION}

Kompas 100:

The Single Index Model. Based on the results of calculations with the formation of an optimal portfolio with a single index model, 33 stocks have a positive ERB value and 1 has a negative ERB value. For optimal portfolio formation, stocks that have a positive ERB are used. Based on the value of $\mathrm{C}^{*}$, the portfolio formed is as follows:

Table 1 - Optimal Portfolio Performance Kompas 100: The Single Index Model

\begin{tabular}{|c|c|c|}
\hline No & Company & Stock Proportion (\%) \\
\hline 1 & UNVR & 15.63 \\
\hline 2 & BBCA & 11.48 \\
\hline 3 & PTPP & 14.45 \\
\hline 4 & BJBR & 11.36 \\
\hline 5 & PWON & 10.08 \\
\hline 6 & TLKM & 9.75 \\
\hline 7 & BBTN & 8.90 \\
\hline 8 & ICBP & 8.64 \\
\hline 9 & BBNI & 4.30 \\
\hline 10 & PNBN & 3.37 \\
\hline 11 & PLNF & 2.04 \\
\hline
\end{tabular}

Source: Data processed, Microsoft Excel.

In Kompas 100, the optimal portfolio performance measured using the Single Index Model shows that UNVR has the largest proportion and PLNF has the smallest proportion.

The Constant Correlation Model. In Constant Correlation Model, stocks that have a higher or equal value of excess return to standard deviation (ERS) to the value of the cutoff point are stocks that will form an optimal portfolio.

Table 2 - Optimal Portfolio Performance Kompas 100: The Constant Correlation Model

\begin{tabular}{|c|c|c|}
\hline No & Company & Stock Proportion (\%) \\
\hline 1 & BBCA & 17.82 \\
\hline 2 & TLKM & 14.67 \\
\hline 3 & UNVR & 14.21 \\
\hline 4 & BBNI & 12.80 \\
\hline 5 & BBTN & 9.98 \\
\hline 6 & PTPP & 9.87 \\
\hline 7 & PWON & 8.84 \\
\hline 8 & BJBR & 7.00 \\
\hline 9 & ICBP & 4.80 \\
\hline
\end{tabular}

Source: Data processed, Microsoft Excel.

In Kompas 100, the optimal portfolio performance measured using the Constant Correlation shows that BBCA has the largest proportion and ICBP has the smallest proportion.

The Markowitz Model. In Kompas 100, the optimal portfolio performance measured using the Markowitz Model shows that BBCA has the largest proportion and PLNF has the smallest proportion.

Based on Table 1, 2 and 3, it can be seen that the Single Index Model has a return of 0.001062, the Constant Correlation Model has a return of 0.001028 , and the Markowitz 
Model has a return of 0.001024 . Thus, the Single Index Model is superior compared to the other two models.

Table 3 - Optimal Portfolio Performance Kompas 100: The Markowitz Model

\begin{tabular}{|c|c|c|}
\hline No & Company & Stock Proportion (\%) \\
\hline 1 & BBCA & 25.39 \\
\hline 2 & TLKM & 16.23 \\
\hline 3 & PTPP & 12.00 \\
\hline 4 & BJBR & 11.15 \\
\hline 5 & ICBP & 9.43 \\
\hline 6 & PWON & 8.86 \\
\hline 7 & BBNI & 4.94 \\
\hline 8 & PNBN & 4.53 \\
\hline 9 & PNBN & 4.53 \\
\hline 10 & PLNF & 1.49 \\
\hline
\end{tabular}

Source: Data processed, Microsoft Excel.

Table 4 - Comparison of Optimal Portfolio Performance Kompas 100

\begin{tabular}{|c|c|c|c|}
\hline \multicolumn{4}{|c|}{ The Optimal Portfolio Performance Kompas 100 } \\
\hline $\mathrm{n} / \mathrm{n}$ & The Single Index Model & The Constant Correlation Model & \multirow{2}{*}{ The Markowitz Model } \\
\hline $\mathrm{E}(\mathrm{IDR})$ & 0.001062 & 0.001028 & 0.001024 \\
\hline$\sigma \mathrm{p}$ & 0.013632 & 0.013257 & 0.013332 \\
\hline Sharpe Index & 0.064869 & 0.064112 & 0.063462 \\
\hline Treynor Index & 0.000736 & 0.000692 & 0.000720 \\
\hline Jensen Index & 0.000659 & 0.000619 & 0.000625 \\
\hline
\end{tabular}

Source: Data processed, Microsoft Excel.

The level of risk faced can be calculated using the standard deviation ( $\sigma p)$. Of the three models above, the standard deviation of the Single Index Model has a value of 0.013632 , the Constant Correlation Model has a value of 0.013257 , and the Markowitz Model has a value of 0.013332 . This shows that the Constant Correlation Model has the lowest risk. According to Niranjan Mandal (2013), the optimal portfolio calculation model with the Sharpe's Single Index Model is easier than using the Markowitz's Mean-Variation Model and this model can show how risky a security is if security is stored in a well-diversified portfolio.

Based on Table 4 above, the performance of Kompas 100 stocks can be seen:

Sharpe Index. The Single Index Model has a value of 0.064869 , Constant Correlation Model has a value of 0.064112 and Markowitz Model has a value of 0.063462 ; these results show that the Single Index Model has the highest performance. J. Francis Mary and G. Rathika (2015) show that of 10 companies studied using the Sharpe Single Index Model, only one becomes an investment destination-the one having high performance. Besides that, Meenakshi and Sarita (2012) state that the Sharpe Single Index Model is very simple and useful for optimal portfolio construction.

Treynor Index. The Single Index Model has a value of 0.000736 , the Constant Correlation Model has a value of 0.000692 , and the Markowitz Model has a value of 0.000720. Of the three models, the Single Index Model has the highest performance.

Jensen Index. The Single Index Model has a value of 0.000659 , the Constant Correlation Model has a value of 0.000619 , and the Markowitz Model has a value of 0.000625 . Of the three models, the Single Index Model has the highest performance.

Thus, it can be concluded that the Single Index Model is the best optimal portfolio because it has the highest performance value using the Sharpe, Treynor, and Jensen Index. Niranjan Mandal (2013) confirms that the development of an optimal portfolio investment by using that Sharpe Single Index Model is easier and more comfortable.

LQ 45:

The Single Index Model. For LQ 45, 17 stocks have a positive ERB value, and the data is used to form a portfolio. The value of $\mathrm{C}^{*}$ is in AKRA, which has the highest $\mathrm{Ci}$ value of 
0.000480. Based on the $C^{*}$ value, the portfolio is formed from ICBP, UNVR, TLKM, BBCA, $\mathrm{BBNI}$, and AKRA. The largest optimal portfolio proportion is BBCA.

Table 5 - Optimal Portfolio Performance LQ 45: The Single Index Model

\begin{tabular}{|c|c|c|}
\hline No & Company & Stock Proportion (\%) \\
\hline 1 & BBCA & 26.72 \\
\hline 2 & UNVR & 25.34 \\
\hline 3 & TLKM & 20.72 \\
\hline 4 & BBNI & 15.47 \\
\hline 5 & ICBP & 10.77 \\
\hline 6 & AKRA & 0.96 \\
\hline 7 & UNTR & 0.02 \\
\hline
\end{tabular}

Source: Data processed, Microsoft Excel.

The Constant Correlation Model. With the calculation of the constant correlation model, UNTR has the highest $\mathrm{Ci}$ value of 0.025741 . Based on the $C^{*}$ value, the optimal portfolio proportion is formed from BBCA, UNVR, BBNI, TLKM, ICBP and UNTR shares. The largest proportion is UNVR and the smallest is TLKM.

Table 6 - Optimal Portfolio Performance LQ 45: The Constant Correlation

\begin{tabular}{|c|c|c|}
\hline No & Company & Stock Proportion (\%) \\
\hline 1 & BBCA & 27.71 \\
\hline 2 & UNVR & 22.10 \\
\hline 3 & TLKM & 22.81 \\
\hline 4 & BBNI & 19.90 \\
\hline 5 & ICBP & 7.48 \\
\hline
\end{tabular}

Source: Data processed, Microsoft Excel.

The Markowitz Model. With Markowitz Model, BBCA has the highest portfolio proportion and lowest AKRA.

Table 7 - Optimal Portfolio Performance LQ 45: The Markowitz Model

\begin{tabular}{|c|c|c|}
\hline No & Company & Stock Proportion (\%) \\
\hline 1 & BBCA & 24.37 \\
\hline 2 & UNVR & 25.40 \\
\hline 3 & TLKM & 19.27 \\
\hline 4 & BBNI & 16.92 \\
\hline 5 & ICBP & 9.95 \\
\hline 6 & UNTR & 2.16 \\
\hline 7 & AKRA & 1.93 \\
\hline
\end{tabular}

Source: Data processed, Microsoft Excel.

According to Ihsan Kulali (2016), the Markowitz Model provides the best solutions in many alternatives, which are used with the mean-variance approach. Based on the 3 descriptions above, it can be seen that BBCA has the highest portfolio performance followed by UNVR and TLKM. ICBP, UNTR and AKRA have a proportion of stocks below $10 \%$. Comparison of optimal portfolio performance from LQ 45 stocks using the 3 models above is presented in Table 8:

Table 8 - Comparison ofOptimal Portfolio Performance LQ 45

\begin{tabular}{|c|c|c|c|}
\hline \multicolumn{2}{|c|}{ Optimal Portfolio Performance LQ45 } & \multirow{2}{*}{ The Markowitz Model } \\
\hline & The Single Index Model & The Constant Correlation Model & 0.000953 \\
\hline $\mathrm{E}(\mathrm{IDR})$ & 0.000958 & 0.000950 & 0.013113 \\
\hline $\mathrm{op}$ & 0.013775 & 0.013142 & 1.178054 \\
\hline Bp & 1.171869 & 1.190387 & 0.059087 \\
\hline Sharpe Index & 0.056622 & 0.058716 & 0.000658 \\
\hline Jeynor Index & 0.000666 & 0.000648 & 0.000554 \\
\hline
\end{tabular}

Source: Data processed, Microsoft Excel. 
Based on table 8 it can be seen that Single Index Model has a return of 0,000958, Constant Correlation Model of 0,000950 and Markowitz Model of 0,000953. From these results indicate that the Single Index Model has the highest return, it shows that the Single Index Model is superior compared to the Constant Correlation Model and Markowitz Model. To measure the level of risk faced, standard deviation is used. The standard deviation with Single Index Model is 0.013775 , Constant Correlation Model of 0.013142 and Markowitz Model is 0.013113. Of the three models above, the lowest risk level is the Markowitz Model.

Based on table 8 above, the performance of LQ 45 stocks are as follows:

Sharpe Index. Calculation of the proportion of optimal portfolio shows that the Single Index Model has a value of 0.056622 , the Constant Correlation Model has a value of 0.058716 , and the Markowitz Model has a value of 0.059087 . From these results, the Markowitz Model has the highest performance.

Treynor Index. Calculation of the proportion of optimal portfolio shows that the Single Index Model has a value of 0.000666 , the Constant Correlation Model has a value of 0.000648 , and the Markowitz Model has a value of 0.000658 . From these results, the Single Index Model has the highest performance.

Jensen Index. Calculation of the proportion of optimal portfolio shows that the Single Index Model has a value of 0.000560 , the Constant Correlation Model has a value of 0.000548 , and the Markowitz Model has a value of 0.000554 . From these results, the Single Index Model has the highest performance.

Based on the above, it can be concluded that Markowitz Model is the best optimal portfolio because it has the highest performance value on the Sharpe Index. This is in line with the recommendations of Fadila Paramitha and Achmad Herlanto Anggono (2013) stating that if investors want to calculate or make their own portfolios, they can use the Markowitz Modern Portfolio Theory because this method can help investors make portfolios easier.

Comparison of Optimal Portfolio Performance Kompass 100 and LQ 45. Based on optimal portfolio performance formed on Kompass 100 and LQ 45, the followings can be known:

- Kompas 100 has an optimal portfolio return of 0.001062 , while LQ 45 has an optimal portfolio return of 0.000958 . This shows that the Kompas 100 optimal portfolio has the highest return compared to LQ 45 or that Kompas 100 is superior compared to the LQ 45 stock index;

- Kompas 100 has a standard deviation value of 0.013632 and LQ 45 of 0.013775 . This shows that Kompas 100 has the lowest standard deviation, which means the level of risk possessed is lower than that of LQ 45 stocks;

- Based on the calculation of the Sharpe Index, Kompas 100 has an optimal portfolio proportion of 0.064869 (the Single Index Model) and LQ 45 has a value of 0.056622 (the Markowitz Model). This shows that Kompas 100 has the highest performance.

- In the Treynor Index, it can be seen that Kompas 100 has an optimal portfolio proportion of 0.000736 and LQ 45 of 0.000666 . This shows that Kompas 100 has the highest performance;

- In the Jensen Index, it can be seen that Kompas 100 has a performance value of 0.000659 and LQ 45 has a value of 0.000560 . This shows that Kompas 100 has the highest performance or that Kompas 100 is also superior in the Jensen Index compared to the optimal portfolio of the LQ 45 stocks.

The optimal portfolio formed based on the Single Index Model on Kompas 100 is the best optimal portfolio because it has the highest performance value on Sharpe, Treynor, and Jensen Index. This shows that stocks investors should choose are proportions formed based on the optimal portfolio of the Single Index Model on Kompas 100. Gautam, J., \& Singh, S. (2014)confirm that with the Markowitz model based on several assumptions regarding investor behavior, a single asset portfolio is considered efficient if there are no other assets or portfolios that offer higher expected returns. 


\section{CONCLUSION}

The formation of an optimal portfolio with the Single Index Model, the Constant Correlation Model, and the Markowitz Model in Kompas 100 and LQ 45 stocks produces different proportions of optimal portfolios. The optimal portfolio proportion with the highest return is generated in Kompas 100 using the Single Index Model method. Stocks that have the lowest risk are Kompass 100 using the Constant Correlation Model and LQ 45 using the Markowitz Model method. These results are in line with the research conducted byUmanto (2008), That the formation of an optimal portfolio with a constant correlation model has a better performance compared to the optimal portfolio formed using the single index model.The Constant Correlation Model and the Markowitz Model produce higher returns than return on $\mathrm{JCl}$.

The research conducted by Ayu (2013) also supports this research, that the Single Index Model and the Constant Correlation Model can be used to form an optimal portfolio.

Kompas 100 portfolio has the highest Sharpe, Treynor, and Jensen Index values compared to the LQ 45 portfolio with the Single Index Model, the Constant Correlation Model, and the Markowitz Model. This shows that the optimal portfolio in Kompas 100 has better performance than the optimal portfolio formed in LQ 45. These results are in line with the research conducted by Setiawan (2012) that the optimal portfolio formed in Kompas 100 shares is more optimal than the optimal portfolio formed in stocks in Business Index 27.

For optimal portfolio using the Single Index Model, the highest performance is in Kompass 100 using the Sharpe, Treynor, and Jensen Index compared to LG 45. This shows that the optimal portfolio calculation with the Single Index Model has better performance than Constant Correlation Model and Markowitz Model for both Kompas 100 and LQ 45. J. Francis Mary and G. Rathika (2015) confirm that an efficient portfolio can be achieved with a single index model as proposed by Sharp. The results of this study are in accordance with Ayu (2015) that optimal portfolio performance in the form of the Single Index Model has a better performance than the optimal portfolio formed by the Constant Correlation Model.

\section{REFERENCES}

1. Ayu, D. (2013). "Optimal Portfolio Construction (A Case Study of LQ45 Index in Indonesia Stock Exchange)". International Journal of Science and Research (IJSR) ISSN (Online): 2319-7064 Index Copernicus Value (2013): 6.14 | Impact Factor. p: 4.438.

2. Elton, G. (2013), "Modern Portofolio Theori", 9 Edition". Wiley. United States of America, p. 189

3. Paramitha, F.\& Anggono, A. (2013), "Performance Analysis And optimal Portfolio Diversification of Fourteen Stocks of Lq-45 Index Period 2007 - 2012 Using Markowitz Modern Portfolio Theory", Journal of Business and Management, Vol. 2, No.1, p: 29-38

4. Francis, M.J. \& Rathika, G. (2015), "The Single Index Model And The Construction Of Optimal Portfolio With Cnxpharma Scrip", International Journal of Management (IJM), Volume 6, Issue 1, January (2015), p. 87-96

5. Gautam, J. \& Singh, S. (2014). The Single Index Model \& the Construction of Optimal Portfolio: A Case of Banks Listed on NSE India. SSRN. Retrieved from https://doi.org/10.2139/ssrn.2441450

6. Husnan, S. (2005), "Dasar-Dasar Teori Portofolio \& Analisis Sekuritas", Edisi Keempat, Unit Penerbit dan Percetakan AMP YKPN, Yogyakarta, P.1034-105.

7. Kulali, I. (2016), "Portfolio Optimization Analysis with Markowitz Quadratic MeanVariance Model", European Journal of Business and Management, Volume 8, No. 7, p. 73-79.

8. Mandal, N. (2013). Sharpe' s Single Index Model and Its Application to Construct Optimal Portfolio: An Empirical Study. Yale-Great Lakes Center for Management Research, 7(1), 1-22.

9. Mangram, M.E. (2013), "A Simplified Perspective of the Markowitz Portfolio Theory", Global Journal of Business Research, Volume 7, No. 1, p. 60-66. 
10. Meenakshi, R. \& Sarita, B. (2012), Optimal portfolio selection with or without the procedure of short sales, Asian Journal of Research in Business Economics and Management, Vol. 2, Issue: 7, 220-234.

11. Nugroho, M. (2018), "Performance System of Stock Portfolio during Investment Decision Making Using Constant Correlation Model in Business Index 27 and Idx30", International Journal of Research in Humanities and Social Studies Vol. 5, Issue 8, 2018, pp. 49-61.

12. Partono, T., Widiyanto, Yulianto, A., \& Vidayanto, H. (2017). The Analysis of Optimal Portfolio Forming with Single Index Model on Indonesian Most Trusted Companies. International Research Journal of Finance and Economics, (Issue 163 September, 2017), 50-59.

13. Pinasthika, N. \& Surya, B.A. (2014), "Optimal Portfolio Analysis With Risk-Free Assets using index-Tracking And Markowitz Mean Variance Portfolio Optimization Model", Journal Of Business And Management, Vol . 3, No .7, p. 73 7-751.

14. Sari, T. N., Lesmana, D.C., \& Setiawaty, B. (2017), "Performance Analysis of Optimal Portfolio of Sharia and Conventional Stocks Using Constant Correlation Model", International Journal of Engineering and Management Research, Volume-7, Issue-5,p. 31-35.

15. Suryani, A., \& Herianti, E. (2015). The Analysis of Risk Adjusted Return Portfolio Performance Share for LQ 45 Index in Indonesia Stock Exchange in 2010-2014 Periods. Procedia - Social and Behavioral Sciences, 211, 634-643. https://doi.org/10.1016/j.sbspro.2015.11.087

16. Umanto, E. (2008), "Analisis dan Penilaian Kinerja Portofolio Optimal Saham-Saham LQ45", Bisnis \& Birokrasi.Jurnal IImu Administrasi dan Organisasi, Vol.15, No. 3, p. 178187.

17. Yolanda. (2017), “ Capital Adequacy Ratio And Its Influencing Factors On The Islamic Banking In Indonesia", Journal of Islamic Economics and Business (IKONOMIKA), Volume 2, No 2, p: $162-176$.

18. Yolanda \& Sumarni (2018), "Financial Performance And Factors Influencing Its Banking Companies In Indonesia Stock Exchange". Russian Journal of Agricultural and SocioEconomic Sciences (RJOAS), 3(75), March, p. 63-72.

19. Zubir, Z. (2013), "Manajemen Portofolio: Penerapannya dalam Investasi Saham". Jakarta: Salemba Empat. 